\title{
Mechanical Effects of Brushing with Brazilian Red Propolis Toothpaste on Artificial Teeth
}

\author{
Luanda Ashley Menezes Estácio, Viviane Solano Lutif, Lara Choairy Adeodato, Márcio Glauber Lopes de Aguiar, Isabelly de Carvalho Leal, \\ Paulo Goberlânio Barros Silva, Nicole de Mello Fiallos, Analice Mendes Barreto Fernandes, João Hildo de Carvalho Furtado Júnior*, \\ Carlos Ricardo de Queiroz Martiniano, Emmanuel Arraes de Alencar Júnior, Said Gonçalves da Cruz Fonseca, Ana Cristina de Mello Fiallos \\ Federal University of Ceará, Fortaleza-CE, BRAZIL.
}

\begin{abstract}
Objectives: The objective of this study was to verify the effect of brushing on the mass, color and roughness of the acrylic resin artificial teeth of the RDP, using a dentifrice incorporated with $1 \%$ Brazilian Red Propolis (BRP) after 5 years of brushing. Methods: The specimens were distributed in 3 groups / 10 each: Distilled Water (DW), 1\% BRP-based dentifrice (PD) and Positive Control dentifrice (CD), analyzed before and after 24, 36 and 60 months of brushing. Data were expressed as mean and standard deviation, submitted to the Kolmogorov-Smirnov normality test and compared by Friedman or Kruskal-Wallis tests followed by the Dunn post test ( $p<0.05$, GraphPad Prism 5.0). Results: It was found that the mass had a statistically significant reduction over time, the color was observed that all experimental groups showed a significant variation $(\triangle \mathrm{E})$ and roughness did not show significant variations between groups over time. Conclusion: It was concluded that 1\% BRP-based dentifrice
\end{abstract}

did not cause deleterious effects on the surface of acrylic resin artificial teeth after 5 years of brushing. However, further in vivo and in vitro studies should be performed to evaluate their long-term use and then confirm their effectiveness in sanitizing RDP.

Key words: Dental Prosthesis, Propolis, Toothbrushing, Natural Products, Dentistry.

Correspondence

Dr. João Hildo de Carvalho Furtado Júnior

Dentist, Professor Federal University of Ceara, Fortaleza - CE, 60020-181, BRAZIL.

Email: jhildocarvalho@gmail.com

DOI: 10.5530/jyp.2021.13.27

\section{INTRODUCTION}

The lack of hygiene of Removable Dental Prostheses (RDP) can cause several diseases, ${ }^{1}$ since the oral cavity is colonized by several pathogens and this microbial reservoir can cause various infections, including prosthetic stomatitis (PS) clinically presents as erythema and inflammation in the oral mucosa covered by the prosthesis area. ${ }^{2}$ The lack of mechanical disorganization of the prostheses increases the capacity of microorganisms such as Candida albicans to colonize oral tissues and RDP, acting as an opportunistic pathogen. ${ }^{2}$

Although this condition can be induced by several factors, one of its most common causes is the formation of polymicrobial biofilm on the surface of the prostheses, which is often associated with Candida species, particularly Candida albicans. Fungal cells adhere easily to the acrylic surfaces of the prosthesis and support adhesion and colonization by oral bacteria. ${ }^{3}$ However, studies indicate that PS associated with Candida is a preventable disease, which can be prevented through proper patient education, maintenance of oral hygiene and prosthesis, as well as regular reviews of the patient's RDP by the dentist. ${ }^{4}$

The first treatment option for PS is the use of topical antifungal agents, such as nystatin, miconazole, amphotericin B, fluconazole, clotrimazole, ketoconazole, chlorhexidine and natural products as propolis, green tea extract, garlic extract, Punica granatum extract, Garcinia kola extract, essential oil of Pelargonium graveolens, essential oil of Satureja hortensis, essential oil of Zataria multiflora boiss. In cases of failure with topical therapy and in immunocompromised patients, systemic antifungals are prescribed. ${ }^{4}$ Clinical evidence suggests that antifungal therapy is only effective for the treatment of inflammation associated with PS if the patient is instructed on the correct use, oral hygiene and prosthesis. Otherwise, the effectiveness of treatment with antifungals is limited, and there may be a rapid recurrence of PS within a short period of time after the end of treatment., ${ }^{2,5}-7$

Among the main methods for cleaning dentures, the mechanic, the chemist and the combination of both stand out, the first being essential. ${ }^{8}$ The mechanical method consists of the association of brushing and the use of dentifrice, as it is simple to use, easy to access and of low cost. However, its main disadvantage is the abrasive action of the dentifrice on the materials that make up the prosthesis. ${ }^{2}$ This abrasive action can cause roughness on the surfaces of the prostheses, which can facilitate the fixation of microorganisms and the development of biofilm. The presence of irregularities, cracks or porosities in the acrylic prosthesis represents a reservoir for the adhesion and colonization of Candida. Chemical cleaning is also indicated for cleaning the RDP in combination with mechanical cleaning. This combination should remove stains, have an antimicrobial action, be easy to use, low cost, without changing the mechanical properties of the RDP materials. ${ }^{2,67,9,10}$

Due to the toxicity of conventional antifungals and the emergence of strains resistant to antifungal drugs, research on natural products in Dentistry has increased in recent years. ${ }^{11,12}$ Among these products, propolis stands out, which has been used in popular medicine for centuries and in Dentistry it stands out due to its anti-inflammatory and antimicrobial potential. ${ }^{13-16}$ After the identification of the first 12 types of brazilian propolis, a new type was described in 2007, red propolis type 13. Among the types of propolis, Brazilian red propolis (BRP) stands out, which has Dalbergia ecastophyllum as its botanical origin (L) Taub. (Leguminosae), which gives propolis a red color. BRP can be found in hives located in the mangrove stem, shrubs and sea and river coasts in northeastern Brazil. The red propolis from the state of Alagoas recently

This is an open access article distributed under the terms of the Creative Commons Attribution-NonCommercial-ShareAlike 4.0 License, which allows others to remix, tweak, and build upon the work non-commercially, as long as the author is credited and the new creations are licensed under the identical terms. 
obtained a Geographical Indication (GI) by the National Institute of Industrial Property (INPI), certified as the only producer of this type of propolis in the world. ${ }^{17,18}$

In this context, considering the antifungal action of BRP, the effect of cleaning the RDP with $1 \%$ of BRP dentifrice on the physical properties (mass and surface roughness) and the color of artificial resin teeth was evaluated.

\section{METHODS}

\section{Specimens}

The specimens used in the study were artificial teeth of acrylic resin (upper central incisors) of the brand Vipi Dent Plus ${ }^{\oplus}$ (VIPI Produtos Odontológicas, Pirassununga, SP, Brazil) in color 60 and model 38. For the correct operation of the brushing machine, the specimens were fixed using a heavy condensation silicone matrix (Reflexdenso ${ }^{\circ}$, Yller Biomateriais S/A, Pelotas, RS, Brazil) and adapted on acrylic discs (30 $\mathrm{mm}$ in diameter and $05 \mathrm{~mm}$ in thickness). The teeth were randomly divided into three groups $(n=10 /$ each), according to the tested substance: distilled water (DW) 1 to 10; propolis dentifrice - test (PD) 11 to 20 and control dentifrice (CD) 21 to 30 .

\section{Tested Substances}

Propolis Dentifrice- Test (PD): A dentifrice incorporated with Brazilian red propolis was formulated (Patent process BR 102017011097 4) with a concentration of $1 \%$ in the region of Marechal Deodoro-Alagoas. For this, it was defined using an $80 \%$ georeferenced extract. The BRP extract, georeferenced from the Federal University of Alagoas (Altitude $35.5 \mathrm{~m}$; Lat South $9^{\circ} 42258^{\prime}$; Lat Oeste $35^{\circ} 54391^{\prime}$ ) was selected, which is the most abundant and studied in the Northeast of Brazil.

The extract was collected in the month of may, according to seasonality studies, being in the period of greatest concentration of chemical constituents. Then, samples were submitted to chemical identification of their constituents using High Performance Liquid Chromatography (HPLC). The extract was acquired by the apiary that supplies the same to the Federal University of Alagoas. The dentifrice was handled by the Pharmacotechnics laboratory at the Faculty of Pharmacy, Dentistry and Nursing at the Federal University of Ceará.

Control Dentifrice (CD): For the control group, Even ${ }^{\circledR}$ commercial dentifrice (Indústrias Reunidas Raymundo da Fonte S / A, Vila Torres Galvão Paulista, PE, Brazil) was used, composed of: Glycerin, Sodium Saccharin, Carboxymethylcellulose, Sorbitol, Sodium Silicate, Pyrophosphate Tetrasodium, Methylparaben, Propylparaben, Calcium Carbonate, Sodium Lauryl Sulfate, Aroma, Water, Sodium Monofluorophosphate.

\section{Groups}

The specimens were randomly assigned to $3 n=10$ groups numbered 1 to 30 .

a) Group DW 1-10 = group of teeth that were cleaned using mechanical brushing with distilled water.

b) Group PD 11-20 = group of teeth that were cleaned using mechanical brushing with BRP based dentifrice.

c) Group CD 21-30 = group of teeth that were cleaned using mechanical brushing with commercial Even ${ }^{\circledR}$ dentifrice.

\section{Brushing Test}

In order to remove any residues from the specimens, acrylic teeth, they were taken to an ultrasonic vat (Unique, - Ultracleaner $1400^{\circ}$, Indaiatuba, São Paulo, Brazil), for $5 \mathrm{~min}$, immersed in distilled water, before and after the brushing tests. Then, dried with absorbent paper and replaced in the silicone matrices.

For the brushing test, soft brushes (Medfio ${ }^{\circledR}$, Pinhais, Paraná, Brazil) were used with soft nylon bristles, containing 34 separate tufts, and the brush handles adapted to fit correctly in the machine brushing (Elquip MSEI $^{\circledast}$, São Carlos, São Paulo, Brazil).

Five years of brushing were simulated, where one year corresponds to 17800 cycles, with a load of $200 \mathrm{~g}$, previously calibrated, on the surface of the specimens. The excursion range of movements in $20 \mathrm{~mm}$ and with a speed of 4.5 movements per second. ${ }^{19}$ The sanitizing substances, test dentifrice (PD), control dentifrice (CD) and distilled water (DW) were injected for $4 \mathrm{sec}$ over the buccal region of acrylic resin teeth, where we demarcate the brushing surface. The temperature of the machine was maintained at $37^{\circ} \mathrm{C}$, on average.

\section{Preparation of Solutions}

The 1:1 ratio was determined for the dilution of the sanitizing substances, $100 \mathrm{~mL}$ of distilled water for each $100 \mathrm{~mL}$ of dentifrice, in order to simulate the dilution that saliva provides during brushing in the oral environment. Subsequently, the dentifrice was placed in injection syringes with a capacity of $20 \mathrm{~mL}$ and adapted to the brushing machine, these were replaced whenever necessary.

The machine was systematized to inject the solutions for $4 \mathrm{sec}$, in cycles of $30 \mathrm{sec}$ and the temperature of the machine was maintained at $37^{\circ} \mathrm{C}$.

\section{Analysis}

The specimens were analyzed before the brushing test (T0), after intervals of 24 months (T2), 36 months (T3) and 60 months (T5) of simulated brushing, totaling four analyzes.

\section{Mass of the Specimens}

In order to analyze possible changes in the mass of the specimens, samples were weighed before and after the simulated brushing tests. For this, we use an analytical electronic scale MARK 210A (BEL Equipamentos LTDA, Piracicaba / SP), with a sensitivity of $0.1 \mathrm{~g}$. At each analysis, the balance was properly calibrated and expected to be energized for $30 \mathrm{~min}$.

\section{Color Stability}

Color reading was performed with the portable spectrophotometer (Vita Easyshade ${ }^{\oplus}$, Vita Zahnfabrik H. Rauter GmbH \& Co, Germany). To quantify the magnitude of the colorimetric difference, we used the relationship $\Delta \mathrm{E}\left(\Delta \mathrm{E}=\left[\left(\Delta \mathrm{L}^{\star}\right) 2+\left(\Delta \mathrm{a}^{*}\right) 2+\left(\Delta \mathrm{b}^{\star}\right) 2\right] 1 / 2\right)$, where $\Delta \mathrm{E}$ represents the tooth's total color divergence, $\mathrm{L}^{\star}$ represents the luminosity, $\mathrm{a}^{*}$ means the red-green chromaticity, and $\mathrm{b}{ }^{*}$, the yellowblue chromaticity of each specimen, using the observation standard recommended by the CIE (Commission Internationale de l'Éclairage), after brushing periods in relation to its initial parameters, a condensing silicone template (Reflexdenso ${ }^{\star}$, Yller Biomateriais S / A, Pelotas, RS, Brazil) and a white screen to ensure standard reading in the center of each specimen and prevent entry $\Delta \mathrm{E}$ values less than 1 were considered as not appreciable by the human eye, between 1 and 3.3, perceptible by specialized observers and, greater than 3.3, perceptible by lay observers and identified as clinically unacceptable.

\section{Surface Roughness}

For the evaluation, three readings $3 \mathrm{~mm}$ apart were carried out on the flatter surface of the buccal surface of each specimen. From there, an arithmetic mean of the deviations of profile roughness ( $\mathrm{Ra}$ ) was obtained with the aid of the Surface Rugosimeter (Hommel Tester T1000 Jenoptik, Jena, Thuringia, Germany). The rugosimeter was programmed to move a diamond tip ( $5 \mu \mathrm{m}$ in radius), following a straight path of 
$4.8 \mathrm{~mm}$ in length and cut off was $0.8 \mathrm{~mm}$. The parameter $\mathrm{Ra}(\mu \mathrm{m})$ was considered.

\section{Statistical Analysis}

The data were expressed as means and standard deviations, submitted to the Kolmogorov-Smirnov normality test and compared by the Friedman or Kruskal-Wallis tests followed by the Dunn post-test $(p<0.05$, GraphPad Prism 5.0).

\section{RESULTS}

Tables 1-3 show the values of the variation in mass, color and roughness, respectively, of the groups distilled water (DW), propolis dentifrice (PD) and positive control dentifrice (CD) after 5 years of simulated brushing. In the intra-group comparative analysis of the specimens of the same group in relation to the experimental times, there was a slight significant reduction in all groups from $\mathrm{T} 2$. There was no significant variation in the comparison between the specimens of the three groups in each experimental period.

With regard to color, in the intra-group comparative analysis of the specimens in relation to the experimental times, a significant variation was observed after 36 months and at the end of five years of simulated experimentation (T5). In the analysis between the specimens of the three groups, in relation to each experimental period, a significant variation was observed in T2. Regarding surface roughness, there was no significant variation in the specimens of the same group (intragroups) in relation to the experimental times and neither in the comparative analyzes between the specimens of the three groups in each period.

\section{DISCUSSION}

This study sought to analyze, in vitro, the effect of a dentifrice incorporated with $1 \% \mathrm{BRP}$ on the mass, color and surface roughness of acrylic resin teeth used in the manufacture of RDP. Artificial RDP teeth play an important role in oral functions, such as chewing and pronunciation, and in preserving facial appearance. Most of the artificial composite resin teeth used have good resistance to fracture but there is still low resistance to discoloration compared to other materials. ${ }^{20}$

The antifungal activity observed against Candida albicans makes BRP an interesting alternative for the cleaning of RDP. ${ }^{21} \mathrm{~A}$ study by Santos et al. ${ }^{22}$ reported the potent antifungal and anti-inflammatory actions of BRP in the form of adhesive gel for the topical treatment of prosthetic stomatitis, gradually removing the signs and symptoms including pain, redness and inflammation-related stomatitis.

No studies were found to evaluate the effect of red propolis extract in the form of dentifrice on the artificial teeth of acrylic resin from the RDP. However, a clinical study conducted on human teeth with gel and dentifrice with $3 \%$ content of ethanol extract of propolis caused an efficient removal of dental plaque and improved the condition of the marginal periodontium. ${ }^{23}$

In the mass analysis, it was observed that the three groups tested showed significant loss of mass during the 5 years of simulated brushing. This significant loss of mass was observed even in the DW group, corroborating with other studies that also obtained a reduction in mass in the group of specimens brushed with distilled water, suggesting that distilled water may produce some level of abrasion and consequent loss of mass. ${ }^{5,24}$ In the study by Sorgini et al. ${ }^{20}$ for example, concluded that

\begin{tabular}{|c|c|c|c|c|c|}
\hline Mass & Tо & $\mathrm{T} 2$ & T3 & T5 & $p$-Value* \\
\hline DW & $0.389 \pm 0.008^{\mathrm{Aa}}$ & $0.388 \pm 0.008^{\mathrm{Ab}}$ & $0.387 \pm 0.007^{\mathrm{Ab}}$ & $0.388 \pm 0.008^{\mathrm{Ab}}$ & $<0.0001$ \\
\hline $\mathrm{PD}$ & $0.394 \pm 0.009^{\mathrm{Aa}}$ & $0.393 \pm 0.009^{\mathrm{Ab}}$ & $0.392 \pm 0.009^{\mathrm{Ab}}$ & $0.393 \pm 0.009^{\mathrm{Ab}}$ & 0.0002 \\
\hline $\mathrm{CD}$ & $0.374 \pm 0.041^{\mathrm{Aa}}$ & $0.373 \pm 0.040^{\mathrm{Ab}}$ & $0.372 \pm 0.040^{\mathrm{Ab}}$ & $0.373 \pm 0.040^{\mathrm{Ab}}$ & $<0.0001$ \\
\hline$p$-Value ${ }^{* *}$ & 0.417 & 0.077 & 0.063 & 0.117 & \\
\hline
\end{tabular}

All the values of mean \pm SD Different lowercase letters $=$ Significant difference between assessment periods within the same group.

Different capital letters $=$ Significant difference between groups in the same evaluation period .

${ }^{\star}$ Friedman / Dunn test; ${ }^{* \star}$ Kruskal-Wallis/Dunn test.

Table 2: Variations of means and standard deviation for color variations in the distilled water (DW), propolis dentifrice (PD) and positive control dentifrice (CD) at (TO) times, after 24-month intervals (T2), 36 months (T3) and 60 months (T5) of brushing.

\begin{tabular}{cccccc} 
Color & T0 & T2 & T3 & T5 & p-Value* \\
DW & $9.730 \pm 0.874^{\mathrm{Aa}}$ & $7.570 \pm 1.546^{\mathrm{Aa}}$ & $10.150 \pm 1.845^{\mathrm{Aa}}$ & $12.130 \pm 2.140^{\mathrm{Ab}}$ & 0.0013 \\
PD & $9.260 \pm 1.135^{\mathrm{Aa}}$ & $6.440 \pm 1.728^{\mathrm{Aa}}$ & $9.470 \pm 3.141^{\mathrm{Aa}}$ & $11.360 \pm 1.830^{\mathrm{Ab}}$ & 0.0002 \\
CD & $9.190 \pm 1.369^{\mathrm{Aa}}$ & $9.210 \pm 2.464^{\mathrm{Ba}}$ & $10.600 \pm 2.508^{\mathrm{Aa}}$ & $11.510 \pm 1.507^{\mathrm{Aa}}$ & 0.0048 \\
-Value $^{* *}$ & 0.691 & 0.018 & 0.557 & 0.283 & \\
\hline
\end{tabular}

All the values of mean \pm SD

Different lowercase letters $=$ Significant difference between assessment periods within the same group.

Different capital letters $=$ Significant difference between groups in the same evaluation period

${ }^{\star}$ Friedman / Dunn test; ${ }^{* *}$ Kruskal-Wallis/Dunn test. 
Table 3: Variations of means and standard deviation for variations in roughness in the distilled water (DW), propolis dentifrice (PD) and positive control dentifrice (CD) groups at (TO), after 24-month intervals (T2), 36 months (T3) and 60 months (T5) of brushing.

\begin{tabular}{cccccc}
\hline $\begin{array}{c}\text { Roughness in the } \\
\text { flatter portion }\end{array}$ & T0 & T2 & T3 & T5 & $p$-Value* \\
\hline DW & $1.061 \pm 0.222 \mathrm{Aa}$ & $1.068 \pm 0.556 \mathrm{Aa}$ & $0.936 \pm 0.288 \mathrm{Aa}$ & $1.042 \pm 0.213 \mathrm{Aa}$ & 0.6685 \\
PD & $1.013 \pm 0.462 \mathrm{Aa}$ & $0.861 \pm 0.144 \mathrm{Aa}$ & $1.029 \pm 0.489 \mathrm{Aa}$ & $0.968 \pm 0.203 \mathrm{Aa}$ & 0.9753 \\
CD & $0.969 \pm 0.269 \mathrm{Aa}$ & $0.974 \pm 0.251 \mathrm{Aa}$ & $0.949 \pm 0.230 \mathrm{Aa}$ & $0.984 \pm 0.095 \mathrm{Aa}$ & 0.4846 \\
$p$-Value $^{* *}$ & 0.529 & 0.311 & 0.965 & 0.473 & \\
\hline
\end{tabular}

All the values of mean \pm SD

Different lowercase letters $=$ Significant difference between assessment periods within the same group .

Different capital letters $=$ Significant difference between groups in the same evaluation period.

${ }^{\star}$ Friedman / Dunn test; ${ }^{* *}$ Kruskal-Wallis/Dunn test.

brushing with toothpaste resulted in greater weight loss than brushing with water in the period of one year.

Regarding color, it was observed that all experimental groups exhibited a significant variation $(\Delta \mathrm{E})$ after 5 years of simulated brushing $(\mathrm{T} 5)$ in relation to T0. However, it is observed that the values of $\Delta \mathrm{E}$ were lower than $3.3(\Delta \mathrm{E}<3.3)$, which is considered internationally as clinically acceptable. ${ }^{25}$ Thus, it became evident that the dentifrice incorporated with $1 \%$ of BRP did not promote clinically significant color variation over the 5 years of simulated brushing. Corroborating with the results obtained here, Roselino et al. ${ }^{26}$ found that the 2 -year simulated brushing with Ricinus communis-based toothpaste (castor) did not cause color changes in artificial teeth when compared with other commercial toothpastes already used for the cleaning of RDPs, (Sorriso Dentes Brancos $^{\circledast}$, Colgate Luminous White ${ }^{\varpi}$ Close up White Now ${ }^{\oplus}$ Trihydral $^{\circledR}$ ). Similarly to this investigation, Panariello et al..$^{27}$ analyzed the color stability of thermopolymerizable acrylic resins, after simulating 90 brushing cycles with distilled water, sodium hypochlorite (1\%), Corega Tabs $^{\circledast}$, chlorhexidine gluconate (1\%) and peracetic acid (0, two $\left.\%\right)$. There were no significant variations and all groups showed clinically acceptable color changes. On artificial teeth of RDP acrylic resin, Carvalho Neto et al. ${ }^{5}$ evaluated the effect of using dentifrice based on Punica Granatum Linné (pomegranate) on surface roughness and alteration color of artificial teeth in brushing for 5 years and concluded that there were no significant changes between the groups analyzed in the period of five years, which corroborates with the present study.

Analyzing the values of $\Delta \mathrm{E}$ of each of the tested groups, after five years of brushing, it is noted that the PD and DW groups had lower means than the CD group. Therefore, although this variation does not have statistical significance, this can be seen as an advantage of propolis dentifrice in relation to the control dentifrice.

The color stability of acrylic resin is an important feature for users of dental prostheses, as discoloration or pigmentation is a sign of aging or damage to the prosthetic structure. In addition, the color of acrylic or base resin teeth harmonize with the patient's biotype, favoring aesthetics. Thus, the loss of these items generates psychosocial discomfort to the user of RDP. Thus, it is essential to use a sanitizer that helps maintain the color of these biomaterials. ${ }^{4,28,29}$

Given the importance of color stability of artificial teeth as one of the essential factors for the maintenance of the prosthesis and the patient's well-being in relation to the aesthetic parameter, the result obtained with brushing using propolis-based dentifrice is positive. Unfortunately, in the analysis of the literature, no studies were found with other herbal medicines that would allow a comparative analysis of the mechanical effects of brushing.

As for surface roughness, the data obtained did not reveal significant statistical changes when the three groups were compared $(p>0.05)$. When comparing specimens from the same group, an increase in roughness of specimens was observed in the T3 groups at T3 (36 months), when compared to the results obtained at T2 (24 months). It is believed that this difference observed between the tested dentifrice groups may have occurred due to the deposition of BRP residues on the surface of the $\mathrm{PD}$ group specimens. Considering that at the end of the 60 months, the roughness decreased again, this difference can be considered irrelevant. On the other hand, it is believed that more investigations are needed to better elucidate this event.

Analysis of the literature suggests that there are still few studies evaluating the effects of tooth brushing with different solutions / dentifrices on the properties of acrylic resin teeth.

\section{CONCLUSION}

The brushing of artificial acrylic resin teeth that make up the RDP with dentifrice incorporated with BRP at $1 \%$ caused loss of mass similar to the other groups tested, the reduction being compatible with results obtained in the literature in relation to the hygiene method In relation to color, it can be noted that all experimental groups exhibited a significant variation $(\Delta \mathrm{E})$ after 5 years of simulated brushing, however, within clinically acceptable parameters and did not significantly alter the surface roughness of the specimens after one five-year period.

\section{ACKNOWLEDGEMENT}

We acknowledge Dr. Lidia Valadas and Ms Mara Lotif for donating the extract, and Federal University of Ceará to support this study.

\section{CONFLICT OF INTEREST}

The authors declare that there is no conflict of interest.

\section{ABBREVIATIONS}

BRP: Brazilian Red Propolis; CD: Control Dentifrice; PD: Test Dentifrice; DW: Distilled Water; HPLC: High Performance Liquid Chromatography; RDP: Removable Dental Prostheses.

\section{REFERENCES}

1. Porwal A, Khandelwal M, Punia V, Sharma V. Effect of denture cleansers on color stability, surface roughness, and hardness of different denture base resins. J Indian Prosthodont Soc. 2017;17(1):61-7. 
2. Gendreau L, Loewy ZG. Epidemiology and etiology of denture stomatitis. J Prosthodont. 2011;20(4):251-60.

3. Hannah VE, O'Donnell L, Robertson D, Ramage G. Denture Stomatitis: Causes, Cures and Prevention. Prim Dent J. 2017;6(4):46-51.

4. Di Stasio D, Lauritano D, Minervini G, Paparella RS, Petruzzi M, Romano A, Candotto V, Lucchese A. Management of denture stomatitis: A narrative review. J Biol Regul Homeost Agents. 2018;32(1):113-6.

5. Carvalho Neto, Diniz TC, Barreto JO, Valadas LAR, Neto EMR, Fiallos NM, et al. Mechanical Brushing Effects in vitro of a Dentifrice Containing Punica granatum Linné. J Young Pharm. 2021;13(1):54-7.

6. Capistrano HM, Assis DEM, Leal RM, Alvarez-Leite ME, Brener S, Bastos EM. Brazilian green propolis compared to miconazole gel in the treatment of Candida-associated denture stomatitis. Evid Based Complement Alternat Med. 2013;2013:947980.

7. Pina GM, Lia EN, Berretta AA, Nascimento AP, Torres EC, Buszinski AF, et al. Efficacy of Propolis on the Denture Stomatitis Treatment in Older Adults: A Multicentric Randomized Trial. Evid Based Complement Alternat Med. 2017:2017:8971746.

8. Gajwani-Jain S, Magdum D, Karagir A, Pharane P. Denture cleansers: A review. IOSR-JDMS. 2015;1(14):94-6.

9. Panzeri H, Lara EH, Hde FP, Silva LDCH, Souza DRF, Gugelmin DSMC, et al. In vitro and clinical evaluation of specific dentifrices for complete denture hygiene. Gerodontology. 2009;26(1):26-33.

10. Gonçalves LFF, Neto DDS, Bonan RF, Carlo HL, Batista AUD. Higienização de próteses totais e parciais removíveis. Rev Bras Ciênc Saúde. 2011;15(1):87-94.

11. Pereira ADS, Seixas FRMS, Neto AFRD. Própolis: 100 anos de pesquisa e suas perspectivas futuras. Química Nova. 2002; 25(2):321-6.

12. Casaroto AR, Lara VS. Phytomedicines for Candida-associated denture stomatitis. Fitoterapia. 2010;81(5):323-8.

13. Schmidt EM, Stock D, Chada FJ, Finger D, Sawaya AC, Eberlin MN, Felsner $\mathrm{ML}$, Quináia SP, Monteiro MC, Torres YR, et al. A comparison between characterization and biological properties of Brazilian fresh and aged propolis. Biomed Res Int. 2014;2014:257617.

14. Yumnam R, Nandan N, Kumar NC, Raj S, Mannepalli A. Effect of propolis in oral health. Journal of J Ayurveda Integr Med Sci. 2017;2(1):186-92.

15. Junior FJHC, Valadas RLA, Mendonça KS, Filho DORD, Gadelha LMU, Fiallos DMN, et al. Propolis and its Dental Applications: A Technological Prospection. Recent Pat Biotechnol. 2018;12(4):288-96

16. Júnior FJHC, Valadas LAR, Fonseca SGDC, Lobo PLD, Calixto LHM, Lima AGF, et al. Clinical and Microbiological Evaluation of Brazilian Red Propolis
Containing-Dentifrice in Orthodontic Patients: A Randomized Clinical Trial. Evid Based Complement Alternat Med. 2020;2020:8532701.

17. Franchin $M$, Freires IA, Lazarini JG, Nani BD, Cunha DMG, Colón DF, et al. The use of Brazilian propolis for discovery and development of novel antiinflammatory drugs. Eur J Med Chem. 2018;153:49-55.

18. Freires IA, Alencar DSM, Rosalen PL. A pharmacological perspective on the use of Brazilian Red Propolis and its isolated compounds against human diseases. Eur J Med Chem. 2016;110:267-79.

19. Freitas DKM, Hde PF. Weight loss of five commercially available denture teeth after toothbrushing with three different dentifrices. J Appl Oral Sci. 2006:14(4):242-6.

20. Sorgini DB, Silva-Lovato $\mathrm{CH}$, Souza DRF, Davi LR, Hde PF. Abrasiveness of conventional and specific denture-cleansing dentifrices. Braz Dent J. 2012;23(2):154-9.

21. Junior BW, Miranda EO, Alvino V, Araujo B, Silva DW, Porfirio Z. Atividade antimicrobiana de frações da própolis vermelha de Alagoas, Brasil. Semina: Ciências Biológicas e da Saúde. 2012;33(1):3-10.

22. Santos VR, Gomes RT, Mesquita DRA, Moura DMD, França EC, Aguiar DEG, et al. Efficacy of Brazilian propolis gel for the management of denture stomatitis: A pilot study. Phytother Res. 2008;22(11):1544-7.

23. Tanasiewicz M, Skucha-Nowak M, Dawiec M, Król W, Skaba D, Twardawa $\mathrm{H}$. Influence of hygienic preparations with a $3 \%$ content of ethanol extract of Brazilian propolis on the state of the oral cavity. Adv Clin Exp Med. 2012:21(1):81-92.

24. Pontes KMF, Holanda DJC, Fonteles CS, Pontes CDB, Silva LDCH, Hde PF Effect of toothbrushes and denture brushes on heat-polymerized acrylic resins. Gen Dent. 2016;64(1):49-53.

25. Johnston WM. Color measurement in dentistry. J Dent. 2009;37(1):e2-6.

26. Roselino LDMR, Alandia-Román CC, Leite VMF, Silva-Lovato CH, Pires-de-Souza FDCP. Color stability and surface roughness of artificial teeth brushed with an experimental Ricinus communis toothpaste. Braz J Oral Sci. 2015;14(4):267-71.

27. Panariello BH, Izumida FE, Moffa EB, Pavarina AC, Jorge JH, Giampaolo ET. Effects of short-term immersion and brushing with different denture cleansers on the roughness, hardness, and color of two types of acrylic resin. Am J Dent. 2015;28(3):150-6.

28. Freitas-Pontes $\mathrm{KM}$, Silva-Lovato $\mathrm{CH}$, Paranhos HF. Mass loss of four commercially available heat-polymerized acrylic resins after toothbrushing with three different dentifrices. J Appl Oral Sci. 2009;17(2):116-21.

29. Freire TS, Aguilar FG, Garcia Lda F, Pires-de-Souza Fde C. Colour stability of denture teeth submitted to different cleaning protocols and accelerated artificial aging. Eur J Prosthodont Restor Dent. 2014;22(1):24-7.

Article History: Submission Date : 25-03-2021; Revised Date : 03-04-2021; Acceptance Date : 04-05-2021.

Cite this article: Fiallos ACM, Estácio LAM, Lutif VS, Adeodato LC, Aguiar MGL, Leal IC, et al. Mechanical Effects of Brushing with Brazilian Red Propolis Toothpaste on Artificial Teeth. J Young Pharm. 2021;13(2):131-5. 